\title{
DAS JANELAS AOS PORÕES: A CONSTRUÇÃO DA SENSIBILIDADE CRIADORA EM CADERNOS DE INFÂNCIA, DE NORAH LANGE
}

\section{FROM THE WINDOWS TO THE BASEMENTS: THE CONSTRUCTION OF AN AUTHOR'S SENSIBILITY IN CADERNOS DE INFANCIA, BY NORAH LANGE}

\author{
Júlia Nunes Azzi ${ }^{1}$ \\ Universidade Federal do Rio Grande do Sul
}

\begin{abstract}
RESUMO
Este trabalho busca analisar a construção do en pela escrita memorialística no livro Cadernos de infância, da escritora argentina Norah Lange. Publicada pela primeira vez em 1937, a obra é composta por diversos fragmentos, que narram eventos da infância da personagem-Norah, os quais se combinam para construir essa identidade individual, ligada a um determinado modo de estar no mundo e um olhar pessoal para as coisas, cujo desenvolvimento é o foco principal de sua narração. Pretende-se examinar alguns aspectos constitutivos dessa escrita, tais como a seleção dos episódios e a linguagem marcada pela poeticidade, buscando destrinchar o (auto)retrato que se propõem a criar. Pensa-se este relato memorialístico como uma procura no terreno fértil da infância pelo eu que se tornará o escritor mais tarde, porém não como uma mera busca no passado, mas uma construção que se dá a partir do ato de lembrar no presente, com todas as ressignificações que acompanham esse movimento. Nesse sentido, este artigo busca analisar três questões fundamentais na narrativa, explorando como elas se conectam na busca por uma coerência, mesmo que dispersa, mas necessária para a criação dessa sensibilidade autoral: 1) a linguagem poetizada e conotativa que exprime os acontecimentos, 2) o enfoque dado ao detalhe, ao minúsculo, aos silêncios entre as palavras 3) a escolha temática por episódios relacionados a mortes, doenças, medos e tudo que apresente alguma fragilidade. Como aporte teórico, utilizam-se textos de estudiosos como Aleida Assmann, Jeanne-Marie Gagnebin, Joel Candau, Mikhail Bakhtin e Michael Pollak, entre outros.

PALAVRAS-CHAVE: Cadernos de infância; escrita memorialística; construção identitária.
\end{abstract}

\begin{abstract}
This assignment seeks to analyze the construction of the self by the memorialistic writing in the book Cadernos de Infância, by argentinian writer Norah Lange. Published for the first time in 1937, the literary work is composed of several fragments, narrating the childhood of the character-Norah, which combine to build this personal identity. This identity is linked to a specific way of being in the world and a personal look at events, and its development is the main focus of the narrative. This paper intends to examine a few of the constituent aspects of this writing, such as the selection of episodes and the language marked by poeticity, looking to unravel the (self) portrait that they set out to create. This memorialistic report is thought of as a search in the fertile soil of childhood for the self that will become the writer at a later point in life, however not in a mere search on the past, but a construction that is given from the act of remembering on the present, with all the reframing that accompany this move. In that sense, this article seeks to analyze three fundamental aspects in the narrative, exploring how they connect to each other searching for some kind of coherence, even if disperse, but necessary for the creation of this authorial sensibility: 1) the poetized, connotative language that expresses these happenings, 2) the focus given to the details, to the minuscule, to the silence between the words, 3) the thematic choice for episodes related to
\end{abstract}

\footnotetext{
${ }^{1}$ Mestranda em Estudos Literários Aplicados, no Programa de Pós-Graduação em Letras, da Universidade Federal do Rio Grande do Sul (UFRGS). E-mail: julianazzi@hotmail.com.
} 
death, diseases, fears and everything that presents some sort of frailty. As a theoretical base, this paper utilizes texts from scholars such as Aleida Assmann, Jeanne-Marie Gagnebin, Joel Candan, Mikhail Bakhtin and Michael Pollak, among others.

KEYWORDS: Cadernos de Infância; memorialistic writing; identity construction.

\section{INTRODUÇÃO}

Publicado pela primeira vez em 1937, Cadernos de infância é uma obra autobiográfica escrita por Norah Lange, que narra momentos de sua vida, da infância até a adolescência, enfocando principalmente seu cotidiano doméstico e a relação com os outros membros de sua família. O livro é formado por capítulos curtos que, como instantâneos, capturam distintos momentos de seu crescimento e vão mostrando a construção de uma subjetividade específica e reconhecível. Em um registro de linguagem que se propõe poético e nessa estrutura de colagem de diversos eventos aparentemente sem relação, tem-se a criação de uma personagem - com todos os matizes ficcionais que uma narrativa memorialística, por mais fiel que se proponha, contém - que apresenta uma visão de mundo muito particular, marcada pela imaginação e capacidade observadora, mas também pela estranheza e por certas obsessões. Lange constrói, a partir da linguagem utilizada e dos eventos escolhidos para narrar, essa sensibilidade inicial, uma sensibilidade de quem - como sabemos pelo inevitável "spoiler" que a classificação do texto como memorialístico carrega - se tornará a futura escritora a narrar suas memórias, mesmo que tanto as memórias quanto a própria escritora sejam sempre construções.

Norah Lange (1905-1972) foi uma poeta e romancista argentina que escreveu, ao longo de sua vida, três livros de poesia e oito livros em prosa. Foi uma figura popular nos anos 1920 e 1930, principalmente por sua vinculação a grupos de vanguarda e por sua ligação com nomes como Oliverio Girondo e Jorge Luis Borges. Por isso, quando publicou Cadernos de infância, aos trinta e dois anos, já gozava de uma certa popularidade como figura literária conhecida. Contudo, nem sempre o fato de ser conhecida implica ser reconhecida, e esse era um caso em que as duas ideias não se equivaliam. Segundo Vicky Unruh (1998), Lange estava menos associada à ideia de autora e muito mais associada ao status de musa de vanguarda, conhecida por sua posição como esposa de Girondo e paixão de Borges, e também por sua personalidade excêntrica e comportamento não convencional, marcado por longos discursos e declamações exaltadas em público.

Tudo isso contribuiu para que ela fosse vista, até mesmo pelos escritores de seu grupo literário, sob o signo da musa, tanto que "os escritores de sua época a denominaram uma fonte de inspiração e uma personificação palpável da nova estética do círculo" (UNRUH, 1998, p. 277). Porém, assim como no caso brasileiro de Patrícia Galvão, sua produção não era tão valorizada quanto sua imagem e o que ela representava. Além disso, até então, Lange voltara-se mais para a poesia, e suas incursões anteriores na prosa não tinham sido bem recebidas pela crítica da época. Levando isso em consideração, pode-se pensar como, com a publicação da autobiografia, há uma tentativa de mostrar um outro lado seu, mais pessoal e, ao mesmo tempo, mais autoral, apresentando com isso um olhar sensível, imaginativo e voltado aos detalhes, aspectos comumente vistos como características essenciais de um escritor.

Cadernos de infância compreende oitenta e dois capítulos, em sua maioria curtos, que narram episódios distintos e fora da ordem cronológica, centrados no cenário doméstico da infância da personagem principal, que nunca é nomeada. O universo do livro focaliza a vida familiar e cotidiana, tendo como espaço principal as casas em que morou na infância e seus arredores. Tratase de um convívio majoritariamente feminino, que dá ênfase às relações com a mãe e, principalmente, as irmãs, enfocando em bem poucos capítulos figuras masculinas como o pai e o

\footnotetext{
2 Tradução minha. No original: “[...] los escritores de su época la denominaron una fuente de inspiración y la palpable personificación de la nueva estética del círculo."
} 
irmão. Há uma exploração desse mundo particular, a partir de um olhar já adulto que procura recuperar ou construir, utilizando-se de metáforas e comparações, um olhar infantil voltado para a observação e apreensão do mundo em seus detalhes.

\section{Nas janelas embaçadas}

Ao descrever a imagem que possui em relação ao pai na infância - em um dos raros momentos em que o personagem aparece - a narradora diz: "parece-me que tem a tristeza daqueles cabeçalhos de cartas, interrompidas não se sabe por qual motivo, e que a gente encontra, muito tempo depois, no fundo de alguma gaveta" (LANGE, 2009, p. 19-20). Em seguida, ao descrever a mãe, afirma: "ela mostrava aquela mirada um pouco arregalada e triste, de tanto olhar para dentro, como a que vi, depois, nas pessoas que estiveram observando o mar" (LANGE, 2009, p. 21). E mais para o fim do livro, ao falar sobre a fome que ela e a família começam a passar, descreve assim: "Seis estômagos adultos em torno de uma toalha à qual os comestíveis não traziam nenhuma presença reconfortante.” (LANGE, 2009, p. 181). Esses três trechos trazem um elemento em comum, que é explorado minuciosamente no andamento do livro: o trabalho poético com a linguagem.

Percebe-se esse trabalho no esmero da escolha vocabular, e no largo uso de metáforas, comparações, metonímias e figuras de linguagem no geral, que ampliam a capacidade expressiva de cada memória. As descrições da mãe e do pai se ancoram em elementos externos que se tornam reconhecíveis no imaginário do leitor. A comparação aumenta a expressividade da imagem e garante uma abertura para essas memórias, acrescendo-as de sentidos e visões posteriores, o que poderia ser visto como uma maneira indireta de alcançar o conteúdo vivo dessas lembranças, para transmiti-las. O pai aparece sob uma comparação que traduz uma imagem de seriedade e de distância, e ao mesmo tempo de inacabamento, algo que nunca pode ser plenamente conhecido. $\mathrm{E}$, assim como a carta, ele é, de fato, reencontrado tempos depois na narrativa, considerando que ele mal é mencionado até o momento de sua morte, em que a narradora comenta: "Quando olho o seu retrato, penso que não o conheço, penso que ele não me conhece.” (LANGE, 2009, p. 121). Dessa forma, esse uso inicial da linguagem traz a relação com o pai que se estende até o fim. Já no terceiro trecho mencionado, a metonímia "estômagos adultos", como uma substituição para as pessoas à mesa, evidencia a fome e, por extensão, a própria escassez da comida, tornando essa vivência muito mais palpável. Ela traz, da lembrança para a linguagem, a sensação da fome, que nesse instante leva os indivíduos a não serem seu todo, seus corpos, suas mentes, mas apenas estômagos: adultos e famintos.

A linguagem de Lange está repleta desses procedimentos criativos que, embora eliminem qualquer ilusão de que se tratasse de mera transposição da visão da criança, potencializam essas lembranças, não pelo nível de realidade do acontecido, mas dos sentimentos provocados. A adulta que escreve, revendo sua vida, está ali e não tem medo de se mostrar. Torna-se claro o quanto essas memórias são uma construção, que passa principalmente pela linguagem. Segundo Jacy Alves Seixas (2001, p. 51), a memória não resgata o real assim como ocorreu, mas o reconstrói, em uma constante atualização; ela 'age 'tecendo' fios entre os seres, os lugares, os acontecimentos (tornando alguns mais densos em relação a outros), mais do que recuperando-os, resgatando-os ou descrevendo-os como 'realmente aconteceram". O que Lange realiza em seu texto é uma tessitura de diferentes vivências, em que seus estatutos de verdade não importam tanto quanto o que significam em termos de narrativa, o que sinalizam sobre aquela que se diz a partir da escrita: o que sinalizam sobre esse outro, personagem que cria para ser. A linguagem, "poetizada", realiza a potência desses acontecimentos e das coisas observadas. Lange diz o mundo como uma forma de dizer-se, em uma escrita de memórias que fala pela e sobre sua própria linguagem.

Pode-se perceber o quanto, por mais simples e aparentemente desvinculados que sejam muitas vezes os eventos narrados, eles possuem um mesmo norte: a preocupação com mostrar essa 
sensibilidade que se forma, em relação às coisas, às pessoas, aos acontecimentos. A linguagem garante essa abordagem, na medida em que se preocupa menos com os fatos crus do que com a forma de vivificá-los, tornando-os palpáveis. Isso demonstra a perspicácia da mão escritora de Lange para a construção desse cenário. Porém, mesmo se nos detivéssemos simplesmente na obra e na narração sendo feita, mesmo se abandonássemos a ideia de um texto de memórias e pensássemos como um romance, narrado por uma personagem completamente fictícia (em que nada mudaria, exceto o pacto estabelecido com o leitor), esse tratamento de linguagem ainda assim se sustentaria pelo tipo de personagem que nos é apresentada. A linguagem sensível e atenta aos detalhes do cotidiano, expandindo-os, está sintonizada com aquilo que a própria linguagem descreve quanto a essa personalidade em formação: uma personalidade estranha e ao mesmo tempo disposta a se afetar. Dessa forma, a história se pauta nessa narradora já adulta, sobre cuja vida atual pouco sabemos, que revisita episódios de sua vida ao acaso, não em busca do acontecimento grande, mas daqueles perdidos no cotidiano, lugar onde cada indivíduo fermenta em si o que vai se tornar.

Segundo Richard Heersmink (2017), estamos sempre criando uma narrativa sobre nós mesmos, integrando continuamente em um todo, de forma holística, diferentes experiências de vida que se tornam importantes. Trata-se não do todo da memória, virtualmente impossível, mas de alguns eventos que, de alguma maneira, parecem nos constituir e, que, em conjunto, farão parte da forma como nos enxergamos. Essa visão pertence às teorias que veem a identidade pessoal como uma narrativa, tendo em vista que condensamos algumas de nossas memórias em uma história sobre nós mesmos para conseguir fazer algum sentido de quem somos, mesmo que seja um sentido inventado. A nossa necessidade de coerência é, de alguma maneira, suprida por essa narrativa própria, "uma história subjetiva e pessoal, que contém uma série de eventos e experiências, todos conectados, que são (essenciais para) o indivíduo"3 (HEERSMINK, 2017). Dessa forma, o que Cadernos de infância traz à tona é a personagem-Norah, que se escreve e que se cria a partir de um modo de olhar para as próprias memórias. Os acontecimentos apresentados não estão ali por acaso, mas porque fazem parte desse todo, sempre incompleto, que é um modo de fazer sentido das vivências a partir daquele que é criado por elas: consciência de si, desejoso de ser. As vivências, aparentemente desconectadas, se colam umas às outras ao formar a narrativa dessa criança/adolescente, que é também a narrativa de uma personalidade excêntrica, frágil, estranha, sensível, afetada pelo que a cerca, sintonizada e ao mesmo tempo em profundo descompasso com o mundo. Em suma, uma poeta?

Talvez a infância tenha muito em comum com o estar-poeta, um pouco pelo olhar encantado e encantatório para o cotidiano, um pouco pela própria fragilidade, o não-saber, o estar deslocado da vida prática e do "mundo dos adultos", que é fundamentado no pragmatismo e na utilidade. Mesmo que essa infância narrada seja cheia de medos e de manias, ela é um lugar que está aberto a isso, onde a imaginação exerce seu poder de criar em torno do que parece banal. Mais tarde isso se torna cada vez mais difícil, como o último capítulo demonstra. Com o momento de passagem para a vida adulta, algo foi perdido: "me afastaria de todas as pequenas incidências, de todos os pequenos medos, de todas as manias... de toda a ternura que percorreu minha infância" (LANGE, 2009, p. 202). Podemos pensar que esse tipo de escrita, ou a literatura no geral, seja justamente uma luta possível contra esse afastamento descrito. Mesmo que essa luta seja sempre perdida (afinal o sujeito que escreve é alguém já afastado dessa terra fértil inicial), escrever, com suas metáforas e seus ritmos, esticando a linguagem para procurar nela algo de novo (ou de antigo) pode ser uma tentativa de recuperar, pela chave da memória, um estado de sensibilidades característico da infância. Dessa forma, podemos perceber o quanto a visão adulta está presente, não tanto em observações, mas na linguagem que se evidencia, no tom poético das metáforas, no

\footnotetext{
${ }^{3}$ Tradução minha. No original: "In sum, a self-narrative is a subjective and personal story with of a series of connected events and experiences that are (essential to) the person".
} 
olhar que se cola à criança, preenchendo as lacunas deixadas pela distância da memória e, principalmente, pelo próprio ato da escrita criadora: a escrita como uma forma de luta contra e no tempo.

Nesse sentido, essa consciência que se volta para o passado tentando entender-se no cenário das próprias narrativas, de acordo com Marya Schechtman (2005, p. 18), "não é mais o conhecimento passivo de que tivemos experiências, mas uma tentativa ativa de fazer sentido dessas experiências e entender aonde estão nos levando". Há um "eu" que, ao olhar para suas lembranças, se percebe como parte desse fluxo que forma a sua vida. Não se trata de um destino ou um determinismo, mas do modo como um indivíduo se faz e se deixa fazer a partir das experiências das quais, escolhendo ou não, participa. E, mais do que isso: do modo como esse eu se diz a partir de sua leitura (muitas vezes inconsciente) dessas experiências, já que o ato de ser está muito ligado à forma de se compreender. É isso que se torna capaz de fornecer um sentido de coerência para aquele que recorda. É esse movimento de percepção de si que é trazido por Lange naquilo que narra.

Além disso, na relação entre o olhar presente (da narração) e o olhar passado (da menina que viveu) é possível perceber um imbricamento mútuo, pois ao mesmo tempo que o olhar presente traz para a narração o passado que o formou, ele também está construindo esse passado. A memória é sempre algo móvel e, especialmente na narração, ela é reconstruída, atualizada, esticada, perfurada, criada, colada em um grande mosaico. Maurice Halbwachs (2006) teoriza sobre a noção da memória como uma construção, que se baseia principalmente nos grupos sociais de que fazemos parte. Dessa forma, as lembranças não são algo fixo nem meramente individual, mas dependem dos lugares em que se está, das pessoas com quem se convive, de todo o contexto atual de uma vida. De acordo com o autor, "a lembrança é uma reconstrução do passado com a ajuda de dados tomados de empréstimo ao presente e preparados por outras reconstruções feitas em épocas anteriores e de onde a imagem de outrora já saiu bastante alterada" (HALBWACHS, 2006, p. 91). Isso se liga também à dimensão criadora que o ato de rememorar sempre carrega consigo. Há elementos imaginários em tudo aquilo que um indivíduo recorda. Novas interpretações são criadas, dando diferentes pesos às lembranças, iluminando mais uns espaços do que outros, no exercício de recriar a imagem de quem somos. De acordo com Joël Candau (2012), o distanciamento do passado permite que enfatizemos certos acontecimentos, para nos elucidarmos, inventariando não o que foi vivido em si, mas aquilo que se tira desse vivido, sua significação para o sujeito, fazendo com que as lembranças sejam "isso que, em um passado filtrado e colocado em forma pelo crivo da memória, consideramos ser a causa do que somos e do que seremos". (CANDAU, 2012, p. 65).

$\mathrm{Na}$ obra de Lange, o presente da narração leva a um olhar renovado para essas lembranças, que se apresentam de uma forma bastante heterogênea, não seguindo uma linha exata, mas se encaixando nesse todo da obra, ligado à construção de uma personagem-Norah. Porém, ao mesmo tempo, o efeito criado pela obra parece ser de reconstrução mais de um estado de espírito do que de uma biografia factual: não a evocação de um determinado objeto, mas de um tipo de subjetividade em formação. As memórias são a captura de um olhar presente na versão infantil daquela que narra, a partir da reconstrução, ou mesmo da invenção - já que as fronteiras entre realidade e ficção nunca são claras. Trata-se da narração de um estado de sensibilidades, de forma que, para chegar a isso, não basta a evocação pura e simples, e sim, o trabalho pela linguagem para trazer um modo de sentir o mundo.

Esse movimento, mais subjetivo, pode ser aproximado do olhar da pintura, que é expressivo e não meramente comunicativo, como aparece na reflexão que Aleida Assmann (2011) faz sobre um poema de Wordsworth, ao explorar a diferença entre a pena e o pincel. Segundo Assmann (2011, p. 104), enquanto a pena (ou seja, a escrita) tem tradicionalmente como

\footnotetext{
4 Tradução minha. No original: "It is no longer a passive knowing that we have had experiences, but a more active attempt to make sense of those experiences and understand where they are leading us"
} 
característica a tentativa de documentar, de fixar, de registrar algo como foi, o pincel tem uma relação maior com a atmosfera: "O pincel não documenta, ele modela uma ambientação". Em Cadernos de infância, as memórias parecem ser trazidas a pincel, menos certeiras, menos factuais, e mais abertas à impressão, aos sentidos, à memória involuntária. A narração dessas lembranças foge do domínio da pena. Ela modela uma atmosfera, não como um documento, um fato, uma comprovação, mas a partir do imprimir das emoções. Isso acontece tanto na descrição dos acontecimentos como dos personagens que a cercam, especialmente as irmãs. Elas estão sempre presentes, porém, ao mesmo tempo não há uma tentativa de criar um retrato fechado de cada uma. São apenas pinceladas demonstrando momentos e aspectos de suas personalidades, o que faz com que, justamente por isso, elas se tornem presenças complexas, marcadas pelo inacabamento que subjaz a cada indivíduo. Isso se mostra principalmente nos primeiros capítulos, em que, sobre cada uma, Lange apresenta recortes muito específicos, acontecimentos pequenos, mas que contêm um pouco, um fragmento, de quem são.

Além disso, é importante considerar que muitas das lembranças passam por um processo de simbolização, na acepção apresentada por Assmann (2011, p. 275), que afirma que "o que é o afeto para as recordações da juventude é o símbolo para as recordações da velhice. [...] A recordação que ganha a força de símbolo é compreendida pelo trabalho interpretativo retrospectivo em face da própria história de vida". Ou seja, em termos de identidade pessoal, os significados que damos a cada lembrança muitas vezes não vêm no momento da percepção, mas são reconstituídos depois, como um símbolo interpretado que se relaciona com diversas outras narrativas sobre as próprias memórias, formando uma ideia quase coesa da própria identidade. Isso está presente, mesmo que de maneira sutil, nas metáforas utilizadas, que são formas de leitura retrospectiva das vivências, dando a elas um sentido.

Um exemplo dessas metáforas de caráter reinterpretativo é a recorrência de menções a janelas ao longo do texto, sendo essa a principal metáfora para a memória na narrativa. O próprio ato de rememorar é descrito como a ação de ver sobre uma janela embaçada. E essa imagem também está presente em um dos momentos iniciais, em que a personagem olha para o pai e para a mãe através de janelas, na tentativa de entendê-los. Além disso, no momento em que o pai morre, a narradora se refere ao acontecimento dessa forma: "A morte do meu pai se estremecia, toda inteira, contra a janela" (LANGE, 2009, p. 120). As janelas reforçam o caráter visual dessas lembranças, juntando em um mesmo símbolo distintas manifestações de memórias afetivas, ao mesmo tempo em que, pela menção ao embaçamento, parecem trazer a ideia de algo que a personagem busca compreender, mas não decifra completamente.

Essa simbolização faz parte de toda tentativa de criar uma biografia, visto que, quando alguém conta sua história, mesmo que sem pretensões, está presente o objetivo de criar um mito individual, ou seja, direcionar a memória por certos caminhos e não outros em uma busca por construir-se como um tipo de totalidade. De acordo com Michael Pollak (1992, p. 204), "a memória é um elemento constituinte do sentimento de identidade [...] na medida em que ela é também um fator extremamente importante do sentimento de continuidade e de coerência de uma pessoa ou de um grupo em sua reconstrução de si”. Então pode-se perceber na escolha das lembranças e, especialmente, do tipo de linguagem que descreve o olhar da criança para o mundo, que Lange procura imbuir de coerência a própria identidade ao narrar suas memórias, mesmo que essa coerência venha principalmente a partir das idiossincrasias.

Até mesmo o caráter fragmentário dos capítulos traz para a narrativa o modo como a memória se comporta. Os capítulos, apesar de apresentarem uma história de vida, não formam uma continuidade, além de muitas vezes mostrarem personagens indefinidos, presenças etéreas, inexplicadas. Dessa forma, espelham a própria memória, em sua feição fragmentária, elíptica, repleta de lacunas e vaivéns. Porém, ao mesmo tempo, a menção a cadernos no título dá a ideia de uma construção que passa pela escrita, não sendo apenas o fluxo da memória sem polimentos, mas uma expressão escrita de suas movimentações. Assim sendo, podemos enxergar a narração como 
pequenas capturas desse fluxo, anotações dispersas em cadernos, que vão construindo essa realidade pessoal, esse modo de estar.

\section{A cordilheira e o ruído da colher}

Nos fragmentos que compõem o livro, é perceptível que são relativamente poucos aqueles que falam de acontecimentos que poderiam ser considerados "importantes", se considerarmos o que costuma ser narrado de uma trajetória de vida. A maior preocupação não se dirige aos fatos em si, nem há uma tentativa de apresentar como uma unidade o andamento de sua vida a partir de marcos formais. Os acontecimentos mais marcantes na narrativa são, no geral, episódios de perdas: a ida de Buenos Aires para Mendoza e, mais tarde, a ida de Mendoza para Buenos Aires; a despedida da preceptora; a morte da irmã e a morte do pai. Esses são os eventos que, embora disponham, em sua maioria, de apenas um capítulo para cada, mais ecoam ao longo da narrativa, sendo também os que mais trazem fatos palpáveis da biografia da autora. No entanto, o enfoque ao longo de boa parte dos capítulos é dado ao mais "desimportante": casos cotidianos, descrições de pensamentos, impressões ligeiras, conversas entre as irmãs, observações singelas, pequenos eventos que se enchem de relevância nessa rememoração. Ao mesmo tempo, porém, não se pode dizer que os acontecimentos narrados sejam descrições da rotina: são, geralmente, pequenos desvios dentro do prosaico. Trata-se de uma narração de pretéritos perfeitos, mais do que imperfeitos. Os acontecimentos são descritos como únicos, estranhos, singulares - ainda que toda essa singularidade esteja sempre circunscrita à lógica doméstica.

Nesse sentido, podemos realizar uma aproximação entre a escrita de Norah Lange e um tipo de autobiografia abordado por Mikhail Bakhtin (1997): o sócio-doméstico. Esse modelo autobiográfico é apresentado em oposição à biografia estilo aventura-heróica, em que o foco são os acontecimentos extraordinários vividos pelo protagonista. No tipo biográfico sócio-doméstico, o foco está na observação do entorno, no amor às pessoas e às coisas em volta, no cotidiano "não estar no mundo e ter importância nele, mas estar com o mundo, observá-lo, vivê-lo e revivê-lo outra vez" (BAKHTIN, 1997, p. 175). Nesse caso, a ação não é tão importante quanto o ato de vivenciar plenamente esses afetos. As memórias de Lange trazem aspectos desse modo de pensar a biografia, em que o que importa nunca é o grandioso, a aventura, a conquista, mas aquilo que se encontra nesse mundo pequeno da casa, do pátio, do olhar pelas janelas. Mesmo que esses afetos não sejam sempre positivos, como nos casos em que tematiza o medo, ainda assim são afetos, que tornam marcantes esses momentos cotidianos. Todos os acontecimentos narrados têm em comum o foco na construção dos sentimentos, trazendo para a narração momentos que, mesmo simples, têm importância por estarem ligados ao ato de afetar-se.

Esse enfoque na memória afetiva e naquilo que perfaz o cotidiano está presente, por exemplo, quando são narradas as noites de sábado, que estão entre os momentos mais felizes da menina: "Sinto, às vezes, uma saudade arrebatadora, uma saudade parecida com a que só nos deixam as coisas pequeninas e simples, os acontecimentos mais ingênuos. É a lembrança das noites de sábado, que vem até mim em uma grande onda de ternura e de pureza" (LANGE, 2009, p. 77). Há um reconhecimento da importância das coisas menores. São considerados acontecimentos ingênuos porque não vivem apenas em si só, mas trazem o olhar da criança que os vive, com um entendimento mais inocente, menos poluído pelas vivências posteriores. Por isso, lembrar a infância acaba sendo uma tentativa de se colocar sobre as lentes desse primeiro olhar, mesmo com a noção de sua impossibilidade, considerando que a narrativa de memórias "é sempre questão de construção, uma significação que se constrói posteriormente” (ASSMANN, 2011, p. 149).

Essas memórias afetivas são essenciais na construção de uma imagem dessa infância perdida, e a narração segue um pouco da aparente aleatoriedade que guia os acontecimentos que se tornam memória. Segundo Jean-Yves e Marc Tadié (1999), o afeto é a maneira mais potente de fixar em nós uma lembrança, e independe completamente da vontade - seja de lembrar ou de esquecer - de quem vivenciou o acontecimento. "Tudo é afeto: nossa vida está em relação 
permanente com os objetos, os seres, a vida, nós mesmos" "TADIÉ, 1997, p. 104), e quando essa carga afetiva se torna muito intensa, em relação a determinados eventos, ela cria o vínculo que os levam a serem lembrados. A partir do afeto, algumas dessas memórias podem influenciar completamente a personalidade de uma pessoa, mesmo que ela não queira. Nessa linha, podemos pensar sobre as memórias narradas no livro como parte do universo afetivo de uma criança que se forma, que se cria, e vai se tornando aquela que escreve justamente a partir de sua relação com os acontecimentos marcantes de sua vida. Não os tradicionalmente marcantes, mas aqueles perdidos nas dobras do cotidiano, escondidos nos cantos da casa, que inadvertidamente carregam em si o conhecimento do mundo.

O afeto não escolhe o tamanho ou a grandeza daquilo a que se cola. Seguindo as setas desse afeto, a narração valoriza as coisas pequenas, muitas vezes frágeis, que se tornam o foco do olhar. Essa valorização do miúdo, do rés-do-chão, é trazida pela adulta que recorda e escreve, e surge como efeito desses sentimentos guardados. Porém, isso também aparece como parte essencial da personalidade da criança retratada, que é construída como um olhar observador e curioso, especialmente para o minúsculo e para o frágil. Quando Lange classifica seu texto como uma narrativa de memórias, ela possibilita que o leitor - envolto no pacto autobiográfico - aglutine na imagem da criança-personagem a imagem da criança-real, que desconhecemos, mas cuja versão adulta escreve o livro que lemos. Nesse sentido, não é errado ver esses atributos de observação, imaginação e até da excentricidade como características que levam aos poucos para um olhar que será de escritora. Nesse ponto, se preenche de sentidos a insistência com que a narração remete ao olhar observador e criativo da criança.

De qualquer forma, esse carinho pelo pequeno e pelo frágil é visível, por exemplo, nos comentários da menina sobre a Cordilheira dos Andes, que é uma presença marcante no cenário de Mendoza, onde vive boa parte da infância:

A mim, a cordilheira nunca havia interessado. A janela a aproximava e a perdia, sem que eu o notasse. Talvez ela me tivesse atraído se alguma porção de sombra lhe houvesse dado contornos de rosto, lhe houvesse concedido um significado doloroso, se não fosse tão evidente que se bastava a si mesma; mas, durante os seis anos que vivemos em Mendoza, nunca cheguei a vislumbrar nela o que mais me interessava em todas as coisas, essa sensação súbita de se sentirem sozinhas, a necessidade de que mudassem de aspecto, de que conhecessem uma humildade e o desamparo. (LANGE, 2009, p. 170)

Nessa visão, há uma procura consciente - ou ao menos consciente na visão adulta - de uma simplicidade e uma fragilidade, até mesmo certa solidão, mas não a grandeza de cada coisa, não aquilo que a ultrapassa. A fala sobre a Cordilheira pode ser vista mesmo como uma maneira de ler toda a narração que ela faz de sua vida, por mostrar aquilo que é valorizado de fato em sua visão: a escolha consciente pelas coisas chãs.

No movimento da adulta que busca capturar uma determinada visão da infância, o modo como os capítulos se apresentam - repletos de pequenas cenas, diálogos, pensamentos sobre o entorno, manias sem motivo - traz o que pode ser chamado de um aprendizado de mistérios, como uma expressão desse olhar sendo criado, do mundo sendo compreendido aos poucos e dos sentimentos ainda se definindo. Os primeiros aprendizados estão ali, entre brincadeiras e angústias. De alguma maneira, o universo doméstico reflete o externo, o maior, que vai progressivamente conhecer. Esse enfoque em seu mundo pequeno e seus aprendizados está relacionado com o fato de o livro ser repleto de silêncios e indefinições. Muitos capítulos versam sobre personagens nãonomeados cujas identidades não ficam claras, pois quando a jornada é em busca da construção de uma sensibilidade e de um aprendizado, importa apenas aquilo que possa incitá-lo; o esclarecimento não é importante para além do necessário à pintura de uma atmosfera.

5 "Tout est affect; notre vie est relation permanent avec les objets, les êtres, la vie, nous-mêmes. 
$\mathrm{Na}$ criação dessa atmosfera, nada é simples o bastante que não possa ser dito. Tudo parece esconder um mistério, um limiar para algo escondido. Assim, ela descreve as brincadeiras e diálogos com as irmãs, os próprios sentimentos, cada agonia, cada medo, por menor que seja, além dos objetos e cenários que a cercam, como as três lajotas solitárias no pátio - tudo com o mesmo grau de atenção e de linguagem elaborada e conotativa. Isso ocorre porque, mesmo quanto a fatos pequenos, os sentimentos que suscitam nas crianças são grandes. É preciso uma agudeza no adulto que rememora - e também a habilidade de saber reconstruir esses estados - para capturar a grandeza que tudo adquire nessa fase: medos ensurdecedores como o de uma mão tocar seu rosto à noite, felicidades enormes como quando a personagem começa a dormir no divã, angústias constantes, como ter sido batizada tardiamente, etc.

Recuperar a grandeza que essas vivências possuem na infância é um trabalho de escavação, em que se busca encontrar esse outro-eu, o eu que se costumava ser. Laura Restrepo (2008, n.p), ao falar sobre a escrita de prosa memorialística, reflete sobre a importância dessa criança que se foi, pois ela parece guardar uma chave, um segredo, que se abra à origem: "essa criança é ao adulto o mesmo que a caixa negra é aos aviões: quando tudo em nós se transforma, ou se destrói, nas recordações de infância permanecem protegidas informações essenciais sobre quem somos, quem fomos e o que quisemos ser" ${ }^{\prime \prime}$. Dessa forma, ao buscar as emoções primitivas pela narração dos acontecimentos, busca-se esse ser de origem, essa pessoa que podia retirar do menor acontecimento emoções tão graúdas.

Além desses acontecimentos pequenos que se tornam grandes pelo olhar da criança, há também, no gosto pelo pequeno, o fato de que mesmo as cenas mais importantes são descritas a partir de pequenos detalhes, reforçando a construção do um olhar perscrutador. Isso pode ser percebido no capítulo que traz a morte de Esthercita, a irmã mais nova. Nessa cena, todos os acontecimentos são descritos a partir das sutilezas que a compõem: o silêncio, os murmúrios, a porta fechada no quarto onde está a menina: "O ruído de uma colher levantou uma interrogação, e de repente chegou-nos um gemido que parecia um grito fatigado antes de subir aos lábios" (LANGE, 2009, p. 127). Nessa escrita de detalhes são os pequenos ruídos que assinalam a presença do que é grande: a doença, a morte.

$\mathrm{E}$ em muitos momentos, não será nem ruído. Aquilo que importa, os sentimentos escondidos, as emoções mais poderosas, muitas vezes não transparecem em palavras, mas naquilo que cala. O silêncio é vital na obra. Pode-se pensar o quanto a criança vive em um mundo de silêncios, visto que, mesmo que insista na fala, há muito que não the é dito, nem as grandes perguntas nem as grandes respostas, nada daquilo que não parece adequado aos seus ouvidos, e mesmo os olhares que não consegue ler. Nada disso se faz acessível. O silêncio está em volta de muitas de suas interações com a família, o que faz com que muito seja feito, e mesmo dito, em silêncio. Os sentimentos dos personagens são revelados mais a partir de suas ações do que de suas palavras. Isso fica evidente em cenas como aquela em que Susana coloca em silêncio sua fita preferida sobre a cabeça de Georgina, que está doente, como uma demonstração de afeto, ou na cena em que a preceptora, antes de ir embora, recolhe terra do jardim e dos quartos para levar consigo: "Havia encontrado a maneira de demonstrar-nos, em silêncio, seu apego à Argentina" (LANGE, 2009, p. 74).

Em diversas ocasiões, os personagens se comunicam por gestos silenciosos, mas que dizem muito de outras maneiras. Além disso, em muitos momentos esses silêncios aparecem não no mutismo dos personagens, mas entre suas próprias palavras. Após a morte da irmã, por exemplo, isso aparece: "Mas a tristeza do quarto vazio, de seu vestido usado, daquilo que nós ainda não lhe podíamos dar, daquilo que se the havia ido por entre as mãos, diante dos seus olhos, ergueu-se em pura angústia por trás dos nossos gestos, de nossas palavras" (LANGE, 2009, p. 158). Nesse trecho,

6 Tradução minha. No original: "Ese niño es al adulto, lo que la caja negra a los aviones: cuando todo en nosotros se transforma, o se destruye, en los recuerdos de infancia permanece protegida información esencial sobre lo que somos, lo que no fuimos, lo que quisimos ser" 
há uma angústia que se ergue por trás das palavras, uma ausência constitutiva, algo que está ali e todos sabem, mas que ao mesmo tempo está no silêncio por trás do dizer.

\section{0 porão como um refúgio}

A linguagem metafórica e o foco estrito, como uma luneta que se dirige aos detalhes para contarem a história, são escolhas estilísticas de como, a partir da narração, construir essa personagem. Porém, é interessante também notar, como parte importante dessa escolha, os objetos para os quais a memória se dirige: quais são os temas centrais que definem a escolha dos episódios e, mais do que isso, a partir dos focos da biografia iluminados pela narração, qual é o tom dessa narrativa, a atmosfera modelada pelas escolhas dos acontecimentos, tendo em vista que há uma "aura" comum em torno dos eventos narrados, um clima que engloba o que é dito.

Por mais que haja uma ternura pela infância e que esse período apareça nas reflexões de adulta como um período feliz, o tipo de situação que ela escolhe para narrar está longe de trazer uma imagem de infância idealizada. Seu relato segue o caminho da fragilidade, em que tudo está envolto por uma aura de medo, morte, doenças, manias, além de uma solidão nem sempre dita, mas que contorna a narrativa, dando um ar mais frágil a essa infância, mesmo que ela seja descrita em outros momentos sob o signo da ternura. Há uma tensão, em que a felicidade do período é declarada ao mesmo tempo que o que de fato se traz à letra são, em sua maioria. momentos ímpares, de reflexões tristes, cheios de pequenas angústias, ou às vezes estranhos até beirar o grotesco. A maioria das lembranças sempre parece carregar consigo uma carga de melancolia, misturada às incertezas e aos medos.

Na leitura que Jeanne-Marie Gagnebin (1997) faz de Walter Benjamin, a autora afirma que há um interesse por elaborar a infância em uma experiência que é sempre dupla, por não apenas remeter ao acontecido, mas irromper da reflexão do adulto, que lembra a partir de seu presente, descobrindo novos signos e sinais interpretáveis. A questão é que essa infância não se apresenta como algo idealizado, repleto de ingenuidade, mas é um período de incompletude e de desorientação, em que não se possui propriamente as palavras para as coisas nem a habilidade de caminhar em um mundo de adultos. Esse período "contém a experiência preciosa e essencial ao homem do seu desajustamento em relação ao mundo, da sua insegurança primeira, enfim, da sua não-soberania" (GAGNEBIN, 1997, p. 182) e, consequentemente, lembrar-se dela é encontrar-se com um mundo que não está dado, com palavras que escapam, com objetos que não se sabe manusear. Voltar-se à infância é tentar conceber no pensamento "essa ausência originária e universal de linguagem, de palavras, de razão, esse antes do logos que não é nem silêncio inefável, nem mutismo consciente, mas desnudamento e miséria no limiar da existência e da fala" (GAGNEBIN, 1997, p. 183), que nos faz encarar nossa própria incompletude. Nessa linha, é importante pensar no quanto Cadernos de infância encarna essa dimensão incerta, desajustada, tateante desse período inicial. A infância continua envolta em uma aura de ternura apesar de todos os sentimentos negativos, justamente porque talvez não se trate de um "apesar". Talvez toda essa fragilidade seja um encontro fundamental com o desajuste que gera a própria capacidade de criação.

O aspecto temático mais visível ao longo do livro são as frequentes menções ao medo. Apesar de serem vários capítulos curtos narrando momentos muito distintos entre si, em trinta e três desses capítulos o medo aparece de alguma maneira. Há sempre algo que a atemoriza, e muitos desses capítulos são completamente centrados nesse sentimento, desenvolvendo-o. Nesses muitos casos em que o medo aparece, os elementos que o causam são diversos, porém geralmente são relacionados a fatos e objetos cotidianos, que, no olhar detalhista da protagonista, ganham uma relevância enorme. Isso é significativo da valorização da experiência sensível como forma de compreensão da realidade. $\mathrm{Na}$ infância, a própria cisão entre o eu e o mundo é menor, o que leva a uma maior qualidade expressiva: o mundo sentido com os dedos, com os olhos, no domínio dos 
sentidos. Tudo é vivenciado de forma diferente da que pauta a vida adulta. Os medos são cotidianos, frutos do universo doméstico que é sentido intensamente; são pulsões baseadas naquilo que surge dentro desse microcosmos, como uma apreensão do profundo que está além da superfície, mesmo no terreno aparentemente raso de brincadeiras e conversas infantis.

Isso explica também as constantes menções a mortes, doenças, anomalias. Há uma procura pela fragilidade, a partir de uma intuição para o trágico que há na existência, e que, sendo uma reconstrução ou uma completa ficcionalização, forma essa personagem atenta àquilo que foge do ordinário. Há mesmo um desejo por penetrar no misterioso, no obscuro, naquilo que se esconde sob a superfície calma dos móveis. É como se cada coisa escondesse um mistério e mesmo uma perversão e, nesse sentido, há um tom quase aproximado ao gótico em alguns pontos de sua narração, principalmente se pensarmos o gótico feminino, como no caso das irmãs Brontë, em que há uma forte sensação de isolamento e aquilo que é estranho irrompe dentro das paredes de um ambiente doméstico. A vida da menina não é repleta de grandes tragédias, mas Lange apresenta um tipo de olhar sintonizado na frequência do vulnerável e do estranho, procurando esses elementos no cotidiano, e efetivamente achando, mesmo que a partir da invenção. Sobre a relação entre crianças e a morte, José Carlos Rodrigues (2006, p. 21) afirma que "[...] é a partir do momento em que a criança toma consciência de si mesma como indivíduo que ela se sente afetada pela morte", o que corrobora a visão da história como de formação da personagem enquanto um sujeito, a partir de sua relação com o mundo, visto que de alguma maneira a consciência da morte lhe dá consciência da própria vida.

Além desses pontos, também há diversas menções a manias, tanto dela como das irmãs, ou seja, ações que fogem ao estritamente racional e que não possuem um sentido lógico ou pragmático. As manias existem porque existem: há algo de inevitável e inexplicável em sua constituição. Recordar é como sentir de novo essas necessidades, fugir ao domínio da racionalidade, reconstruir o olhar que a criança possui, trazendo a importância daquilo que extrapola a lógica e o senso de praticidade. O movimento de recordação busca recuperar esse momento de estranhamento constante, em que o mundo ainda não é familiaridade plena e o olhar se permite estar perplexo.

Trata-se, no geral, de um olhar para aquilo que está implícito, obscuro, misterioso: submerso. Desse modo, pode-se estabelecer uma relação temática entre essa forma de ver, essa busca, esse aprofundamento naquilo se oculta (mesmo na própria mente) e a seguinte passagem, que fala sobre a relação da personagem com o porão de sua casa:

\footnotetext{
Até muitos anos mais tarde, foi inútil fugir de nossos temores absurdos e inauditos; ao menor sinal de perigo olhávamos para o porão, como se esse refúgio sobressaltado por teias de aranhas, cheio de tijolos úmidos e de sombras, significasse uma permanente, uma imutável segurança (LANGE, 2009, p. 141)
}

Esse trecho demonstra a predominância de medos, mas ao mesmo tempo apresenta a imagem do porão como uma espécie de refúgio, apesar de seu caráter sombrio. A imagem dessa parte da casa tem relações com as partes mais ocultas de nossa psique, como assinala Gaston Bachelard (1993, p. 209), quando afirma que "ele é em primeiro lugar o ser obs-curo da casa, o ser que participa das potências subterrâneas. Sonhando com ele, concordamos com a irracionalidade das profundezas." Pode-se dizer que na história há uma busca por proteger-se nos lugares submersos, onde não achamos geralmente segurança. Os medos, a morte, a doença, o estranho e o inexplicável, tudo isso são terrenos mergulhados, definitivos para a construção dessa sensibilidade, e até mesmo um refúgio para a criança que intui as profundezas de um mundo ainda não formulado pela racionalidade da visão adulta.

A própria fragilidade da personagem é valorizada: seus medos e manias, aquilo que ainda busca de forma muito incipiente compreender. Isso leva ao final simbólico. No último capítulo, ao "enfrentar" o antigo jardineiro, é como reconhecer em si uma força que até então não se manifestara completamente. E nesse momento há um reconhecimento da perda da infância, 
daquele "outro" que começa a se gestar, o que só reforça mais o caráter frágil e "menor" do mundo doméstico, que era o que enfrentara até então. Após esse momento, que ocupa a função de um símbolo na interpretação que a narradora faz de sua vida, há o mundo a ser enfrentado, exigindo uma força que a criança não tinha, e cuja ausência a constituiu, em sua incompletude. Esse instante fecha a imagem criada por Norah Lange para a construção da própria sensibilidade, que se mantém coerente ao longo do livro, e que também se relaciona com a própria linguagem que constitui a obra - uma linguagem que busca justamente retomar essa fragilidade e essa incompletude.

\section{CONSIDERAÇÕES FINAIS}

Em Cadernos de infância, a narração memorialística se coloca a partir de fragmentos, como pequenos retalhos de lembranças que formam um mosaico. Nesse mosaico memorialístico, nunca se atinge a completude de um todo, porque se trata de retalhos que não podem reconstituir tudo o que foi e também porque o todo talvez nem chegue a existir. De qualquer modo, é preciso selecionar, escolher aquilo que se diga, trechos que signifiquem e se ressignifiquem mutuamente, memórias que expressem, que se liguem mesmo que na aparente aleatoriedade; tudo com o objetivo maior, que é o objeto de toda intenção autobiográfica: construir uma subjetividade a partir das palavras. Trata-se de uma busca por algo que está na origem, uma busca que é ao mesmo tempo uma construção e que está sempre atrás de algo que não pode ser plenamente recuperado.

Esse é o movimento que ocorre na obra: a partir de certos fragmentos alinhados há uma formação identitária: a construção de uma personagem para representar o eu do passado, que não se pode de fato alcançar. Compõe-se um determinado olhar para o mundo. O quanto há de sustentação na memória (que mesmo quando se propõe verdadeira, sempre é falha) e o quanto há de pura invenção ao criar a personalidade dessa criança-Norah não importa. O que importa é a coerência que se constrói internamente, na qual todos os elementos, mesmo que diversos, se complementam e formam esse retrato que é expressivo, mesmo se formado por cacos e apresentado por vislumbres, como por uma janela embaçada.

A linguagem poética, repleta de figuras de linguagem e de um grande cuidado vocabular, já é uma interpretação, um modo de trazer o que cada memória tem, não de real, mas de mais significativo, a partir do olhar da criança. O apego aos detalhes, aos não ditos, às sutilezas, que transparecem na narração, são retratos dessa sensibilidade construída e de uma espécie de procura. Os episódios escolhidos e, dentro desses episódios, a iluminação que é colocada em certos aspectos, revelam o tipo de narrativa que Norah Lange resolve dar para sua infância: uma que se baseia na sensibilidade do olhar para o detalhe e para o profundo, que se revela na linguagem poética que a compõe, e que é sintomática de sua tentativa de reconstruir o passado sob o signo da futura escritora.

\section{REFERÊNCIAS BIBLIOGRÁFICAS}

ASSMANN, Aleida. Espaços da recordação: formas e transformações da memória cultural. Tradução de Paulo Soethe. Campinas: Editora da UNICAMP, 2011.

BACHELARD, Gaston. A poética do espaço. Tradução de Antonio de Pádua Danesi. São Paulo: Martins Fontes, 1993.

BAKHTIN, Mikhail. A autobiografia e a biografia. In: Estética da criação verbal. Tradução de Maria Emsantina Galvão G. Pereira. São Paulo: Martins Fontes, 1997, p. 164-181.

CANDAU, Joël. Memória e Identidade. Tradução de Maria Letícia Ferreira. São Paulo: Contexto, 2012 
GAGNEBIN, Jeanne-Marie. "Infância e pensamento". In: Sete aulas sobre linguagem, memória e história. 2. ed. Rio de Janeiro: Imago, 1997.

HALBWACHS, Maurice. A memória coletiva. Tradução de Beatriz Sidou. São Paulo: Centauro, 2006.

HEERSMINK, Richard. "The narrative self, distributed memory, and evocative objects". Synthese: International Journal for Epistemology, Methodology and Philosophy of Science, 194 (8), Dordrecht: Springer Netherlands, 2017.

LANGE, Norah. Cadernos de infancia. Tradução de Joana Angélica D’Avila Melo. Rio de Janeiro: Record, 2009.

POLLAK, Michael. "Memória e identidade social". In: Estudos Históricos. vol. 5, no. 10. Rio de Janeiro, 1992, p. 200-212.

RESTREPO, Laura. Extraño enano. EL PAÍS, Madrid, 03 maio, 2008. Disponível em http://www.elpais.com/articulo/narrativa/Extrano/ enano/elpepuculbab/20080503elpbabnar_15/Tes. (último acesso em 13 de agosto de 2020)

RODRIGUES, José Carlos. "Morte e consciência: pensar o impensável". In: O tabu da morte. Rio de Janeiro: Editora Fiocruz, 2006.

SCHECHTMAN, Marya. Personal identity and the past. Philosophy, Psychiatry and Psychology, 12 (1), Baltimore, Maryland: John Hopkins University Press, 2005, p. 9-22.

SEIXAS, Jacy Alves. Percursos da memória em terras de história: problemáticas atuais. In: BRESCIANI, Stella e NAXARA, Márcia (orgs.). Memória e (res)sentimento: indagações sobre uma questão sensivel. Campinas, Editora da UNICAMP, 2001, p. 37-58.

TADIÉ, Marc; YVES, Jean. Acquisition des souvenirs. In: Le sens de la mémoire. Paris: Gallimard, 1999, p. 95-123.

UNRUH, Vicky. "Las ágiles musas de la modernidad: Patrícia Galvão y Norah Lange". Revista Iberoamericana, Vol. LXIV, Núms. 182-183, enero-junio 1998, p. 271-286.

Submetido em 25/08/2020

Aceito em 16/11/2020 